\title{
Caveolin-1 Polymorphisms in Coronary Artery Disease
}

M Asker ${ }^{1}$, M Taspinar ${ }^{2}$, H Koyun $^{3}$, A Akyol ${ }^{1}$, S Akdag ${ }^{1}$

\section{Affiliations:}

${ }^{1}$ Department of Cardiology, Yuzuncu Yil University Faculty of Medicine, Van, Turkey

${ }^{2}$ Department of Medical Biology, Yuzuncu Yil University Faculty of Medicine, Van, Turkey

${ }^{3}$ Biometry and Genetic Unit, Yuzuncu Yil University Faculty of Agriculture, Van, Turkey

\section{Correspondence:}

Dr M Asker

Department of Cardiology

Medical Faculty

Van Yuzuncu Yil University

65100, Van

Turkey

Fax: +904322121954

E-mail: muntecepasker@mynet.com

Short title: Heart Disease and Caveolin-1

Synopsis: Coronary atherosclerosis is a major cause of mortality. T29107A specific genotype of Caveolin-1 may be linked with coronary artery disease pathogenesis. Utility of this polymorphic variant as a diagnostic or prognostic marker in CAD warrants further trials on larger series. 


\section{ABSTRACT}

Aim: To investigate the associations of G14713A and T29107A polymorphic variants of Caveolin-1 with coronary artery disease (CAD).

Methods: This cross-sectional, clinical study was performed on 194 CAD patients and 114 controls in the cardiology department of our tertiary care center. Descriptive data (age, gender, body-mass index, smoking habit) were noted and biochemical parameters (haemoglobin, hematocrit, serum levels of glucose, lipids, creatinine, mean platelet volume) were evaluated. Genotyping was made for investigating the association of G14713A and T29107A polymorphisms of Caveolin-1 with CAD.

Results: Positivity for Caveolin T29107A was detected significantly more frequently in CAD patients, $(\mathrm{p}=0.009)$, while such a difference could not be observed for Caveolin G14713A $(\mathrm{p}=0.064)$. Coronary artery disease patients had higher body mass indices, mean platelet volumes, serum levels of blood glucose, cholesterol, triglycerides, low-density lipoproteins, creatinine compared to the control group.

Conclusions: In conclusion, our results have shown that T29107A specific genotype of Caveolin-1 may be linked with CAD pathogenesis. Utility of this polymorphic variant as a diagnostic or prognostic marker in CAD warrants further trials on larger series.

Keywords: Caveolin-1; coronary artery disease; single nucleotide polymorphism. 


\section{INTRODUCTION}

Coronary atherosclerosis is a major cause of mortality especially in industrialized countries. Role of inflammatory pathways in the pathogenesis of atherosclerosis is widely accepted (1). In this process, accumulation and activation of monocytes and macrophages in the vessel wall constitute critical steps that in turn elicit the initial phase of plaque formation and chronic lesion progression. These reactions are followed by acute complications such as plaque rupture and thrombosis $(2,3)$.

Caveolae are plasma cell membrane invaginations that are commonly found on fibroblasts, endothelial and epithelial cells. Caveolin-1 is a protein found in caveolae that functions in the intracellular signalling pathway for processes including fibrosis, vascular proliferation, wound healing, angiogenesis, tissue growth (4-6). In addition to these physiological reactions, it can be involved in some pathological processes such as ischemia and tumour growth (7). Previously, Testa has demonstrated that a single nucleotide polymorphism of Caveolin-1 was linked with carotid arterial media thickness in end stage renal disease patients (8). Caveolin-1, encoded by CAV1 gene located at $7 \mathrm{q} 31.1$, is a marker for caveolae. It is supposed to compartmentalize various signalling molecules and serves as an organization centre (9). Some publications have yielded that caveolae had functions in cholesterol transport and haemostasis and lipid droplet accumulation (10).

To the extent of our knowledge, there is no study conducted on the role of Caveolin-1 genotypes in the pathogenesis of coronary artery disease (CAD) in the medical literature. The purpose of the present study was to investigate whether two polymorphic variants of Caveolin-1, namely G14713A and T29107A, may be linked with coronary artery disease. 


\section{MATERIALS AND METHODS}

Study Design

This cross-sectional, clinical study was carried out in the cardiology department of our tertiary care center. Approval of the local Institutional Review Board (2015-1) and written informed consent from each patient were obtained. This study had been carried out in accordance with the principles of the Helsinki Declaration of 1975, as revised in 2000.

The study was performed on 194 CAD patients (72 women, 122 men) and 114 healthy controls (49 women, 65 men). The average ages for CAD and control groups were $62.27 \pm 10.99$ and $61.07 \pm 10.07$, respectively. Descriptive parameters such as gender, bodymass index and smoking habit were noted for each patient.

Fasting serum samples were obtained early in the morning (between 06.00 A.M and 08.00 A.M) by venipuncture through brachial veins. Blood samples were maintained at $4{ }^{\circ} \mathrm{C}$ subsequent to centrifugation at $3000 \mathrm{rpm}$ for 5 minutes.

DNA Extraction and Genotyping Assay

Approximately $5 \mathrm{ml}$ of peripheral blood collected from all participants had been used for isolation of germline DNA from leukocytes. DNA aliquots were prepared at a concentration of $10 \mathrm{ng} / \mu \mathrm{l}$ for PCRs. Genotyping process was performed according to the technique described by Sambrook et al. (11). The following primers were used for CAV1 genotyping: for G14713A (rs3807987), 5'-CCTTCCAGTAAGCAAGCTGT-3' and 5'CCTCTCAATCTTGCCATAGT-3'; and for T29107A (rs7804372), 5'GCCTGAATtGCAAtCCTGTG-3' and 5'-ACGGTGtGAACACGGACATT-3'. The polymerase chain reaction (PCR) cycling conditions were: 35 cycles total, one cycle at $94^{\circ} \mathrm{C}$ $30^{\prime}, 63^{\circ} \mathrm{C} 1^{\prime}, 72^{\circ} \mathrm{C} 1^{\prime}$. The PCR products were studied for Cav-1 G14713A (cut from 268 bp A type into 66+202 bp G type), and Cav-1 T29107A (cut from 336 bp A type into 172+164 bp T 
type). Pairs of PCR primer sequences and restriction enzyme for each DNA product are displayed on Table 1.

Diagnosis of CAD was established with respect to coronary angiography and severity of disease was estimated according to Gensini scores (12). Gensini score constitutes as an objective method for evaluation of the severity of CAD and also provides additional information on prognosis (13).

The control group consisted of healthy adult volunteers that underwent coronary angiography for suspicion of coronary artery disease. Exclusion criteria were history of malignancy, severe congestive heart failure, valvular cardiac disease, chronic metabolic disorders such as renal or hepatic failure.

\section{Outcome measures}

Main outcome measures under concern were positivity for Cav-1 G14713A and BfaI ve Cav1 T29107A polymorphic variants of Caveolin-1 gene. Moreover, descriptive, clinical and biochemical variables were noted and compared in CAD and control groups. These variables included age, gender, body-mass index, smoking habit, family history for CAD, co-existing systemic diseases such as hypertension, diabetes mellitus, hyperlipidemia, serum levels of glucose, creatinine, total cholesterol, low and high density lipoproteins, triglycerides, as well as haemoglobin, haematocrit and mean platelet volume values.

\section{Statistical analyses}

Analysis of data was made via the IBM SPSS Statistics 20 program (Statistical Package for Social Sciences Inc., Chicago, IL, USA). The conformability of the univariate data to the normal distribution was examined using Kolmogorov-Smirnov test. Parameters that display normal distribution were evaluated with parametric methods, whereas variables without a 
normal distribution were analysed by non-parametric methods. Comparison of 2 independent groups was performed by Independent-Samples T and Mann-Whitney U tests. Comparison of categorical variables was made by Pearson's chi-square, Yates Chi-Square and Fisher's Exact tests. Quantitative variables were expressed as either mean \pm standard deviation or medianinterquartile range. Confidence interval was set at $95 \%$ and a difference was termed as statistically significant if $\mathrm{p}<0.05$.

\section{RESULTS}

Data derived from CAD and control groups in this study is demonstrated in Table 2. There were no remarkable differences between two groups in terms of age $(p=0.340)$, gender distribution $(\mathrm{p}=0.309)$, levels of haemoglobin $(\mathrm{p}=0.089)$, haematocrit $(\mathrm{p}=0.320)$, high density lipoproteins $(\mathrm{p}=0.215)$, and family history of CAD ( $\mathrm{p}=0.064)$. Gensini scores in CAD group was determined as 33.45-26.76 (median-interquartile range).

On the other hand, CAD group had notably increased BMI $(\mathrm{p}=0.002)$, serum levels of fasting glucose $(p=0.009)$, total cholesterol $(p<0.001)$, triglycerides $(p=0.032)$, low density lipoproteins $(p<0.001)$, creatinine $(p=0.027)$ and mean platelet volumes $(p<0.001)$. Frequencies of diabetes mellitus $(\mathrm{p}=0.032)$, hypertension $(\mathrm{p}=0.009)$ and hyperlipidaemia $(p=0.037)$ were significantly higher in patients with CAD.

\section{DISCUSSION}

In this study, we aimed to determine whether expression of two polymorphic variants of Caveolin-1 gene, T29107A and G14713A, were altered in CAD. Our findings indicated that T29107A, but not G14713A, was detected more frequently in CAD patients. 
Clinical studies have demonstrated that statins, by involving diverse signal pathways (such as Caveolin, LOX-1, SR-B1, adenosine, etc.) may enhance the availability of endothelium derived nitric oxide. This is important as a cardiovascular defence mechanism of statins. Therefore, Caveolin-1 seems to be involved in the functions of statins for amelioration of cardiovascular diseases and improvement of cardiovascular outcomes (14).

Experimental studies have been performed to unveil the roles and functions of caveolae and Caveolin-1 gene (15-18). Caveolin-knock out animal models have provided clarification of the possible functions of Caveolin-1 and caveolae in several pathologies (15). Caveolin-1 null mice were found to be resistant to diet-induced obesity, accompanied by increases in plasma levels of VLDL particles and triglycerides, and insulin resistance $(16,17)$. In addition, they exhibit vascular dysfunction especially with defects in endotheliumdependent contractile responses (18).

Caveolin-1 plays role in vascular diseases and processes like sepsis, cancer and fibrosis (18). Evidence has been found for dependence of arterial remodelling on a Caveolin-1 single nucleotide polymorphism genotype in patients with end stage renal disease (8). Reduced Caveolin-1 expression was detected in vascular smooth muscle cells of patients with established atheromatous disease (8).

As far as we know, this is the first trial to identify the association between T29107A variation of Caveolin-1 in CAD patients. Results of the present study suggest that there may be a link between a single nucleotide polymorphism of CAV1 and development of CAD. Since CAD is accompanied by inflammatory, metabolic, vascular and systemic impairments, it is difficult to establish a direct causal relationship. Further trials in future cohorts is warranted to establish whether this gene variant is valuable as a diagnostic or prognostic biomarker. 
Moreover, it must be remembered that elucidation of the effects of single nucleotide polymorphisms of Caveolin-1 may necessitate further methods such as immunohistochemistry or western blotting. Roles of each section or every nucleotide in the regulation of transcription, translation and posttranslation stages of Caveolin-1 gene may be distinct. Complicated interactions of many metabolic, biochemical, genetic and environmental factors must be taken into account during interpretation of these results. Enlarged size of population and combined genomic and environmental trials will allow gathering more refined and realistic data for making healthier extrapolations.

To conclude, results of the present study have yielded that T29107A specific genotype of Caveolin-1 may be linked with CAD pathogenesis. Utility of this polymorphic variant as a diagnostic or prognostic marker in CAD warrants further trials on larger series. 


\section{REFERENCES}

1. Moatti D, Faure S, Fumeron F, Amara Mel-W, Seknadji P, McDermott DH, Debré P, Aumont MC, Murphy PM, de Prost D, Combadière C. Polymorphism in the fractalkine receptor $\mathrm{CX} 3 \mathrm{CR} 1$ as a genetic risk factor for coronary artery disease. Blood. 2001; 97:1925-8.

2. Gerrity RG. The role of the monocyte in atherogenesis: II. Migration of foam cells from atherosclerotic lesions. Am J Pathol. 1981; 103:191-200.

3. Moreno PR, Falk E, Palacios IF, Newell JB, Fuster V, Fallon JT. Macrophage infiltration in acute coronary syndromes: implication for plaque rupture. Circulation. 1994; 90:775-8.

4. Chand S, Holle JU, Hilhorst M, Simmonds MJ, Smith S, Kamesh L, et al. Caveolin-1 single nucleotide polymorphism in antineutrophil cytoplasmic antibody associated vasculitis. PLoS One. 2013; 8:e69022.

5. Thomas CM, Smart EJ. Caveolae structure and function. J Cell Mol Med. 2008; 12:796-809.

6. Schwencke C, Braun-Dullaeus RC, Wunderlich C, Strasser RH. Caveolae and caveolin in transmembrane signaling: Implications for human disease. Cardiovasc Res. 2006; 70:42-9.

7. Gao Y, Zhao Y, Pan J, Yang L, Huang T, Feng X, et al. Treadmill exercise promotes angiogenesis in the ischemic penumbra of rat brains through caveolin-1/VEGF signaling pathways. Brain Res. 2014; 1585:83-90.

8. Testa A, Spoto B, Sanguedolce MC, Parlongo RM, Pisano A, Tripepi G, et al. eNOS and caveolin-1 gene polymorphisms interaction and intima media thickness: a proof of concept study in ESRD patients. Am J Hypertens. 2012; 25:103-8. 
9. Pelat M, Dessy C, Massion P, Desager JP, Feron O, Balligand JL. Rosuvastatin decreases caveolin-1 and improves nitric oxide-dependent heart rate and blood pressure variability in apolipoprotein E-/-mice in vivo. Circulation. 2003; 107:24806.

10. Grilo A, Fernandez ML, Beltran M, Ramirez-Lorca R, Gonzalez MA, Royo JL, et al. Genetic analysis of CAV1 gene in hypertension and metabolic syndrome. Thromb Haemost. 2006; 95:696-701.

11. Sambrook J., Fritsch E.F., Maniatis T., 1982 Molecular clonning a laboratory manual, 2nd edn. Cold Spring Harbor Lobısıçanory Press, Cold Spring Harbor, NY.

12. Gensini GG. A more meaningful scoring system for determining the severity of coronary heart disease. Am J Cardiol. 1983; 51:606.

13. Zencirci AE, Zencirci E, Degirmencioglu A, Karakus G, Ugurlucan M, Gunduz S, et al. The relationship between Gensini score and ST-segment resolution in patients with acute ST-segment elevation myocardial infarction undergoing primary percutaneous coronary intervention. Kardiol Pol. 2014; 72:494-503.

14. Balakumar P, Kathuria S, Taneja G, Kalra S, Mahadevan N. Is targeting eNOS a key mechanistic insight of cardiovascular potentials of statins? J Mol Cel Cardiol. 2012; 52:83-92.

15. Williams TM, Lisanti MP. The Caveolin genes: from cell biology to medicine. Ann Med. 2004; 36:584-95.

16. Razani B, Combs TP, Wang XB, Frank PG, Park DS, Russell RG, et al. Caveolin-1deficient mice are lean, resistant to diet-induced obesity, and show hypertriglyceridemia with adipocyte abnormalities. J Biol Chem. 2002; 277:8635-47. 
17. Cohen AW, Razani B, Wang XB, Combs TP, Williams TM, Scherer PE, et al. Caveolin-1-deficient mice show insulin resistance and defective insulin receptor protein expression in adipose tissue. Am J Physiol Cell Physiol. 2003; 285:C222-35.

18. Razani B, Engelman JA, Wang XB, Schubert W, Zhang XL, Marks CB, et al. Caveolin-1 null mice are viable but show evidence of hyperproliferative and vascular abnormalities. J Biol Chem. 2001; 276:38121-38. 
Table 1: The primer sequences and conditions for polymerase chain reaction and restriction fragment length polymorphism procedures of G14713A and T29107A polymorphisms of Caveolin-1 gene (Hint: F: forward primer; R: reverse primer).

\begin{tabular}{|c|c|c|c|c|}
\hline Polymorphisms & Primer sequences & Restriction enzyme & SNP sequence & DNA fragment size (bp) \\
\hline \multirow[t]{2}{*}{ G14713A } & F:5'-CCTTCCAGTAAGCAAGCTGT-3' & Bfa I & A & $268 \mathrm{bp}$ \\
\hline & R: 5'-CCTCTCAATCTTGCCATAGT-3' & & G & $202+66$ bp \\
\hline \multirow[t]{2}{*}{ T29107A } & F:5'-GCCTGAATTGCAATCCTGTG-3' & Sau3AI & $\mathrm{A}$ & $336 \mathrm{bp}$ \\
\hline & R:5'-ACGGTGTGAACACGGACATT-3' & & $\mathrm{T}$ & $172+164 \mathrm{bp}$ \\
\hline
\end{tabular}


Table 2: Comparative overview of variables under investigation in coronary artery disease and control groups

\begin{tabular}{|c|c|c|c|}
\hline \multirow[t]{2}{*}{ Variable } & \multicolumn{2}{|c|}{ Groups } & \multirow[t]{2}{*}{ p Value } \\
\hline & $\mathrm{CAD}(\mathrm{n}=194)$ & Control $(n=114)$ & \\
\hline Age (years) & $62.27 \pm 10.99$ & $61.07 \pm 10.07$ & 0.340 \\
\hline Gender (male/female) & $122 / 72$ & $65 / 49$ & 0.309 \\
\hline Smoking habit $(\%)$ & 55.2 & 43.0 & $0.01 *$ \\
\hline Body-mass index & $28.36 \pm 3.70$ & $27.01 \pm 3.81$ & $0.002 *$ \\
\hline Fasting plasma glucose $\neq(\mathrm{mg} / \mathrm{dl})$ & $132.57 \pm 79.33$ & $108.24 \pm 35.01$ & $0.009 *$ \\
\hline Total cholesterol $\neq(\mathrm{mg} / \mathrm{dl})$ & $200.31 \pm 42.25$ & $183.11 \pm 39.38$ & $<0.001 *$ \\
\hline Triglycerides $\neq(\mathrm{mg} / \mathrm{dl})$ & $189.02 \pm 85.04$ & $172.39 \pm 92.28$ & $0.032 *$ \\
\hline Low density lipoproteins $\ddagger(\mathrm{mg} / \mathrm{dl})$ & $124.92 \pm 34.07$ & $108.88 \pm 33.71$ & $<0.001 *$ \\
\hline High density lipoproteinsł $(\mathrm{mg} / \mathrm{dl})$ & $37.33 \pm 9.33$ & $39.50 \pm 11.51$ & 0.215 \\
\hline Creatinineł $(\mathrm{mg} / \mathrm{dl})$ & $0.81 \pm 0.24$ & $0.76 \pm 0.17$ & $0.027 *$ \\
\hline Hemoglobin (g/dl) & $14.39 \pm 1.66$ & $14.71 \pm 1.49$ & 0.059 \\
\hline Hematocrit & $43.39 \pm 4.45$ & $43.89 \pm 4.45$ & 0.320 \\
\hline Mean platelet volume (femtolitre) & $9.31 \pm 0.11$ & $8.47 \pm 0.99$ & $<0.001 *$ \\
\hline Hyperlipidemia $(\%)$ & 25.8 & 14.9 & $0.037 *$ \\
\hline Diabetes mellitus (\%) & 31.4 & 20.2 & $0.032 *$ \\
\hline Hypertension $(\%)$ & 55.7 & 40.4 & $0.009 *$ \\
\hline Family history for CAD (\%) & 49.5 & 38.6 & 0.064 \\
\hline Caveolin G14713A positivity (\%) & 0.5 & 3.5 & 0.064 \\
\hline Caveolin T29107A positivity (\%) & 13.4 & 3.5 & $0.009 *$ \\
\hline
\end{tabular}

Abbreviations: CAD: coronary artery disease; *: statistically significant; $\neq$ : expressed as median-interquartile range) 